\title{
MEIOTIC BEHAVIOR OF TANDEM COMPOUND RING X CHROMOSOMES IN DROSOPHILA MELANOGASTER ${ }^{1}$
}

\author{
L. SANDLER AND D. L. LINDSLEY \\ Department of Genetics, University of Washington, Seattle, Washington 98105 , \\ and Biology Division, Oak Ridge National Laboratory, Oak Ridge, Tennessee 37831
}

Received November 14, 1966

\begin{abstract}
A compound $\mathrm{X}$ chromosome is composed of two euchromatically complete, or almost complete, $\mathrm{X}$ chromosome elements attached to a single centromere (Novirski 1954); compound X's are symbolized C(1). The subject of this paper is the tandem compound ring $\mathrm{X}$ chromosome, $\mathrm{C}(1) \mathrm{TR}$, which is composed of two euchromatically complete $\mathrm{X}$ chromosome elements in tandem sequence with a single centromere. The ends of the two elements are attached to each other to form a continuous ring. Because the elements are in tandem sequence, the synaptic configuration of the compound is a spiral. A paired tandem ring in the twostrand stage is shown in Figure 1. In addition to the tandem ring, there are five other compound $\mathrm{X}$ chromosomes: (1) the attached-X (or reversed metacentric), $\mathrm{C}$ (1) RM; (2) the tandem metacentric, C(1) TM; (3) the reversed acrocentric, $\mathrm{C}(1) \mathrm{RA}$; (4) the tandem acrocentric, $\mathrm{C}(1) \mathrm{TA}$; and (5) the reversed ring, C(1)RR.
\end{abstract}

Taken together, the results from compound-X experiments have not yet been rationalized. Attached-X chromosomes (see, for example, Beaple and Emerson 1935; WeLshons 1955) behave according to expectations based on studies of free

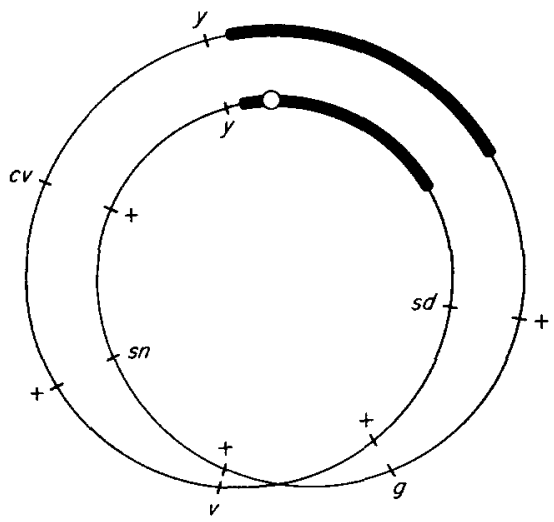

FigURE 1.-A tandem compound ring $\mathrm{X}$ chromosome in the two-strand stage, with the markers used in these experiments.

\footnotetext{
' Research jointly sponsored by Grant RG-9965 from the Public Health Service, and the U. S. Atomic Energy Commission under contract with the Union Carbide Corporation. 
X chromosomes. Tandem metacentrics (Sturtevant and Beadle 1936; NovitSKI 1951; LindsLeY and SANDLER 1965) and tandem acrocentrics (NovitsKI 1954; SANDLER and LindsLey 1963) also exhibit distributions of tetrads of various ranks comparable to free $\mathrm{X}$ chromosomes. They are unstable, however, in that exchange between their component arms generates single $\mathrm{X}$ derivatives. In the females that carry tandem compounds, the recovery of these single $\mathrm{X}$ chromosomes is sensitive to the presence of a Y chromosome or Y-chromosome fragment, the single $\mathrm{X}$ chromosomes being recovered more frequently when the mother carries a Y chromosome than when she does not (Novirskr and SANDLER 1956). It has been shown (Lindsley and SANDLER 1965) that the data from females bearing tandem metacentrics are consistent with the view that newly generated single X's are lost from, or fail to become included in, the zygote nucleus and that this loss is much higher in the progeny of mothers with no Y chromosome.

Reversed acrocentrics (SANDLER 1954) and reversed rings (SANDLER 1957) exhibit a number of peculiarities. First of all, the exchange distribution is abnor$\mathrm{mal}$ in that there is a high frequency of no- and two-exchange tetrads and few, if any, of rank one. Second, in both cases it has been shown that the presence of a whole or partial Y chromosome in the compound-bearing female markedly increases double exchange. In the case of reversed rings, evidence has been adduced which suggests that whereas the ring suffers no viability complications, only about one third of the rings from the no-exchange tetrad class are recovered - the other two thirds being inviable. Finally, although the abnormal tetrad distribution mentioned above normally characterizes reversed acrocentric compounds, a marked change occurs if the long arm of the $\mathrm{Y}$ chromosome is appended to the compound as a second arm: the tetrad distribution becomes similar to that of free $\mathrm{X}$ or attached $\mathrm{X}$ or tandem metacentric or tandem acrocentric chromosomes, and the effect of a homolog on double exchange is reduced or absent (SANDLER 1958).

The tandem ring is the only compound-X chromosome type that has not been subjected to extensive analysis. The first tandem ring was synthesized by NovitSKI (1954), but it lacked heterozygous markers and was therefore of limited utility. Consequently, we have synthesized new tandem rings heterozygous for appropriately positioned markers and have examined their meiotic behavior.

In addition to providing a basis for comparison with other compound types, an analysis of the consequences of exchange in tandem rings is of special interest in two ways. First, in common with other ring chromosomes, expectations vary according to the assumptions made about the occurrence and frequency of sisterstrand exchange. Thus, it is possible to test various assumptions about sister-strand crossing over, particularly the notion that nonsister exchange involves only the two newly synthesized chromatids of the tetrad with sister-strand exchanges which are frequent enough in every region to randomize the strands between successive exchanges (Lindegren and Lindegren 1937; Schwartz 1953). This property is of particular importance because the data from Drosophila for single rings (L. V. Morgan 1933; Novitski 1951, 1955) and for double rings in reversed sequence (SANDLER 1957) are inconsistent with the LiNDEGREN- 
Schwartz assumptions, although consistent with the assumption of no sisterstrand crossing over. Data from a ring in maize, however, are consistent with the sister-strand assumptions, but not with the conventional model (SchWARTz 1953). In nonring chromosomes, the two sets of assumptions are indistinguishable (Weinstein 1936).

Second, although it has been recognized for a long time that ring chromosomes might form interlocked complexes during replication and crossing over, no clear evidence exists in favor of this possibility. Tandem rings represent another instance in which this matter can be examined. Furthermore, tandem rings have the special property that certain exchanges lead to the anaphase separation of a centric ring from an acentric ring, a situation that might have unique consequences.

The data from the present study indicate the following: (1) tandem rings from different constructions behave alike with respect to the exchange distribution, but differ in the proportion of tandem rings transmitted to the progeny; (2) in the absence of a Y chromosome or $\mathrm{Y}$ fragment in the compound-bearing females, there is a reduction in the frequency of double exchange tetrads to less than half that observed from females that carry a Y; (3) the tetrad frequencies in tandem rings closely approximate those of free and attached $\mathrm{X}$ chromosomes, especially those of tandem metacentric and tandem acrocentric compound $\mathrm{X}$ chromosomes; the coefficient of nonrandom disjunction approximates unity as it does for the other tandem compounds; (4) as with other rings in Drosophila, no sister-strand exchange occurs; (5) the progeny of females that carry a tandem ring and a $\mathrm{Y}$ chromosome show no evidence that interlocked complexes, if indeed any are formed, have any effect on the recovery of the various meiotic products; (6) second-anaphase double bridges do not invariably lead to zygote mortality, and in a fraction of the cases they may be eliminated from the egg nucleus to produce nullo-X, nullo-Y ova; and (7) the results from females bearing tandem rings and having no $\mathrm{Y}$ chromosome, although not rigorously analyzable with present techniques, do indicate a variety of responses of the compound to the absence of a homolog.

\section{Synthesis of Tandem Rings}

The tandem ring chromosomes used in these experiments were synthesized in two steps. First, a tandem metacentric compound X chromosome was constructed; then the free ends of its arms were joined to form the tandem ring. The origin of the tandem metacentric has been described by LiNDSLEY and SANDLER (1965). Briefly, females were made heterozygous for (1) an inverted chromosome marked with $s n$ and $g$ and carrying the left end of $\operatorname{In}(1) s c^{8}$ marked by the normal allele of $y$, and the right end of $\operatorname{In}(1) E N$ with its recessive $y$ allele and with $\mathrm{Y}^{\mathrm{L}}$ as a second arm, and (2) a chromosome in normal sequence marked with $y, c v, v$, and $s d$ and carrying distally the $B^{S}$ duplication. This is known as the tandem acrocentrigenic $B^{S}$ duplication [i.e., $D p(1 ; 1) B^{S T} A G$; see LINDSLEY and SANDLER 1963]. These $\mathrm{X} \cdot \mathrm{Y}^{\mathrm{L}}, \ln (1) s c^{8 L} E N^{R}$, sn $g / D p(1 ; 1) B^{S} T A G, y c v v s d B^{S}$ females were $\mathrm{X}$-irradiated with approximately $1500 \mathrm{r}$ and crossed with $y$ males. These 

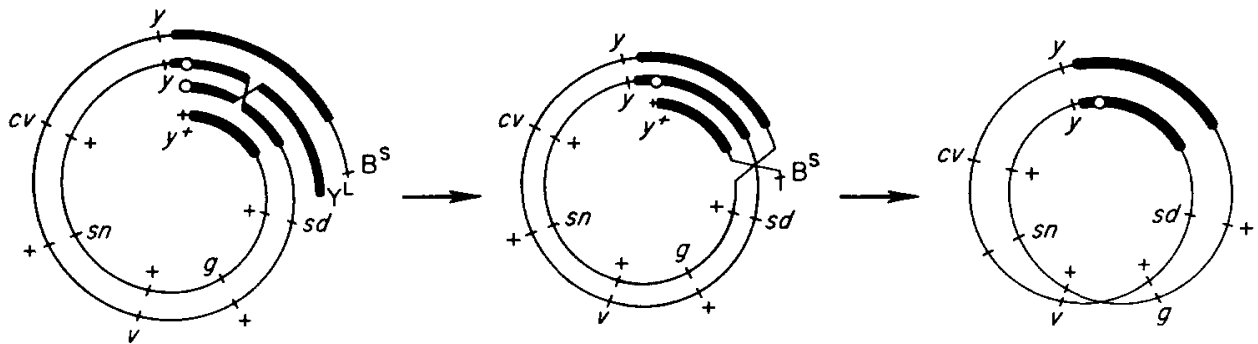

Figure 2.-The origin of the tandem compound ring $\mathrm{X}$ chromosomes used in these investigations. Only two of the four strands are shown. Heavy lines represent heterochromatin, light lines euchromatin.

crosses produced rare matroclinous exceptions, some of which proved to be $\mathrm{C}(1) \mathrm{TM} B^{S}$ formed by crossing over between $\mathrm{Y}^{\mathrm{L}}$ of $\mathrm{X} \cdot \mathrm{Y}^{\mathrm{L}}, \operatorname{In}(1) s c^{s L} E N^{R}$ and the proximal heterochromatin of $D p(1 ; 1) B^{S} T A G$ (Figure 2). Lines of two such tandem metacentrics, $\mathrm{C}(1) \mathrm{TM} B^{s 9} 9$ and $\mathrm{C}(1) \mathrm{TM} B^{\mathrm{s}} 9-4$, were established. Their cytological structure and genetic behavior have been described previously (Lindsley and Sandler 1965).

Progeny of the cross C(1)TMB $B^{s}, \operatorname{In}(1) s c^{s L} E N^{R} \cdot D p(1 ; 1) B^{s} T A G$, sn $g \cdot y c v v s d /$ 0 우 $\times \mathrm{Y}^{\mathrm{s} X} \cdot \mathrm{Y}^{\mathrm{L}}, \operatorname{In}(1) E N, v f B / 0$ o were examined for the presence of $y$ females, i.e., compound-bearing females that had simultaneously lost $y^{+}$and $B^{s}$ from the tips of the two arms of $\mathrm{C}(1) \mathrm{TM} B^{s}$. These were presumptive $\mathrm{C}$ (1) TR-bearing females formed by the exchange shown in Figure 2. Examination of a large number of progeny from both $\mathrm{C}(1) \mathrm{TM} B^{s 9}-1$ and $\mathrm{C}(1) \mathrm{TM} B^{s 9}-4$ females revealed that 9-4 produced many more tandem rings than 9-1 and that $\mathrm{C}(1) \mathrm{TM} B^{\mathrm{S}} / y^{+} \cdot \mathrm{Y}^{\mathrm{L}}$ $\left(y^{+} \cdot \mathrm{Y}^{\mathrm{L}}=\mathrm{FR}-2\right)$ females produced more tandem rings than $\mathrm{C}(1) \mathrm{TM} B^{s} / 0$. These facts are demonstrated in Tables 3 through 6 of our previous paper (LindsLeY and SANDLER 1965). The more abbreviated symbol TR will be used frequently in place of $\mathrm{C}(1) \mathrm{TR}$ in the text below.

\section{Cytology of Tandem Rings}

The cytology of the chromosomes used in the two stages of the synthesis of TR has been described by LINDSLEY and SANDLER (1965). In mitotic figures the TR is a large ring with two euchromatic segments, which are often divided into chromatids separated by two undivided heterochromatic regions, one pericentric and one interstitial. The pericentric heterochromatin, which is the only heterochromatin carried by single ring derivatives [symbolized $R(1)$ ] of $T R$, may be recognized as having the same morphology as that of $\mathrm{C}(1) \mathrm{TM} B^{\mathrm{s}} 9-4$, the tandem metacentric from which it was derived unchanged. The interstitial heterochromatic segment resembles the distal heterochromatin of $D p(1 ; 1) B S T A G$ more than that of $\operatorname{In}(1) s c^{8}$; this is a necessary, but not sufficient, observation for proving that the TR-generating exchange was euchromatic, as diagrammed in Figure 2, rather than heterochromatic.

In salivary configurations the two elements of $C(1) T R$ synapse to form a spiral 
double ring, which is generally indistinguishable from that found in a cell heterozygous for a ring $\mathrm{X}$ chromosome or a long inversion such as $\operatorname{In}(1) E N$. Occasionally, a figure is encountered in which the interstitial heterochromatin is pulled away from the chromocenter, and then the spiral nature of the chromosome becomes apparent.

\section{Expected Behavior of Tandem Rings}

The expectations will be developed based on two different models of crossing over. The first model, the orthodox one, supposes that crossing over occurs exclusively between homologous strands and that there is neither strand preference nor chromatid interference (i.e., that exchange at any level involves a random pair of homologous strands). The alternative model (LiNDEgREN and LiNDEgreN 1937; Schwartz 1953) states that homologous exchange involves only newly synthesized chromatids; sister-strand crossing over, which perforce involves a new and an old strand, is postulated to occur so that in a chromosome segment between two homologous exchanges the number of sister exchanges is sufficiently high to make the chances of an odd or an even number of exchanges virtually the same (i.e., the probability of an effective sister-strand exchange is $50 \%$ ). The double exchanges which are exclusively two-strand are thus converted by sister-strand exchange into two-strand, three-strand, and four-strand doubles in the ratio of $1: 2: 1$.

No sister-strand exchange: The products of no, single, and double exchange between homologous elements of a tandem compound ring $\mathrm{X}$ chromosome are shown in Figure 3. The strands involved can be attached either to the same centromere, i.e., reciprocal exchange (Exchange A, Figure 3), or to sister centromeres, i.e., nonreciprocal or diagonal exchange (Exchange B, Figure 3 ).

Three types of monocentric X-chromosome derivatives are produced by TRbearing females: the single ring, the double ring and the triple ring. We have presented results which suggest that the single ring generated by exchange in tandem metacentric compounds is frequently lost, this loss in turn leading to the production of a nullo-X ovum (LindsLey and SANDLer 1965). When such an ovum is fertilized by $\mathrm{X}$-bearing sperm, an exceptional patroclinous male, which differs from a regular patroclinous male in lacking a maternal $Y$ chromosome, is produced. A similar loss of newly generated single rings in TR crosses may lcad to reduced ring recovery and may provide a source of exceptional patroclinous males. There are three kinds of double ring products; the first is a homozygous $T R$ which is homozygous for regions that were heterozygous in the parental TR. The remaining two products, referred to collectively as nonhomozygous $T R$ 's, are (1) the transposed $T R$, which has the same gene content as the parental TR but in which the phase of the markers (i.e., the coupling relatrons) is altered as a result of diagonal two-strand double exchange (Exchange $A E$, Figure 3) and (2) the matroclinous $T R$, which is identical to the parental TR in both gene phase and content. Finally, the triple ring is considered to result in zygote mortality when the coefficient of nonrandomness is low enough to permit its inclusion in the functional egg nucleus. 


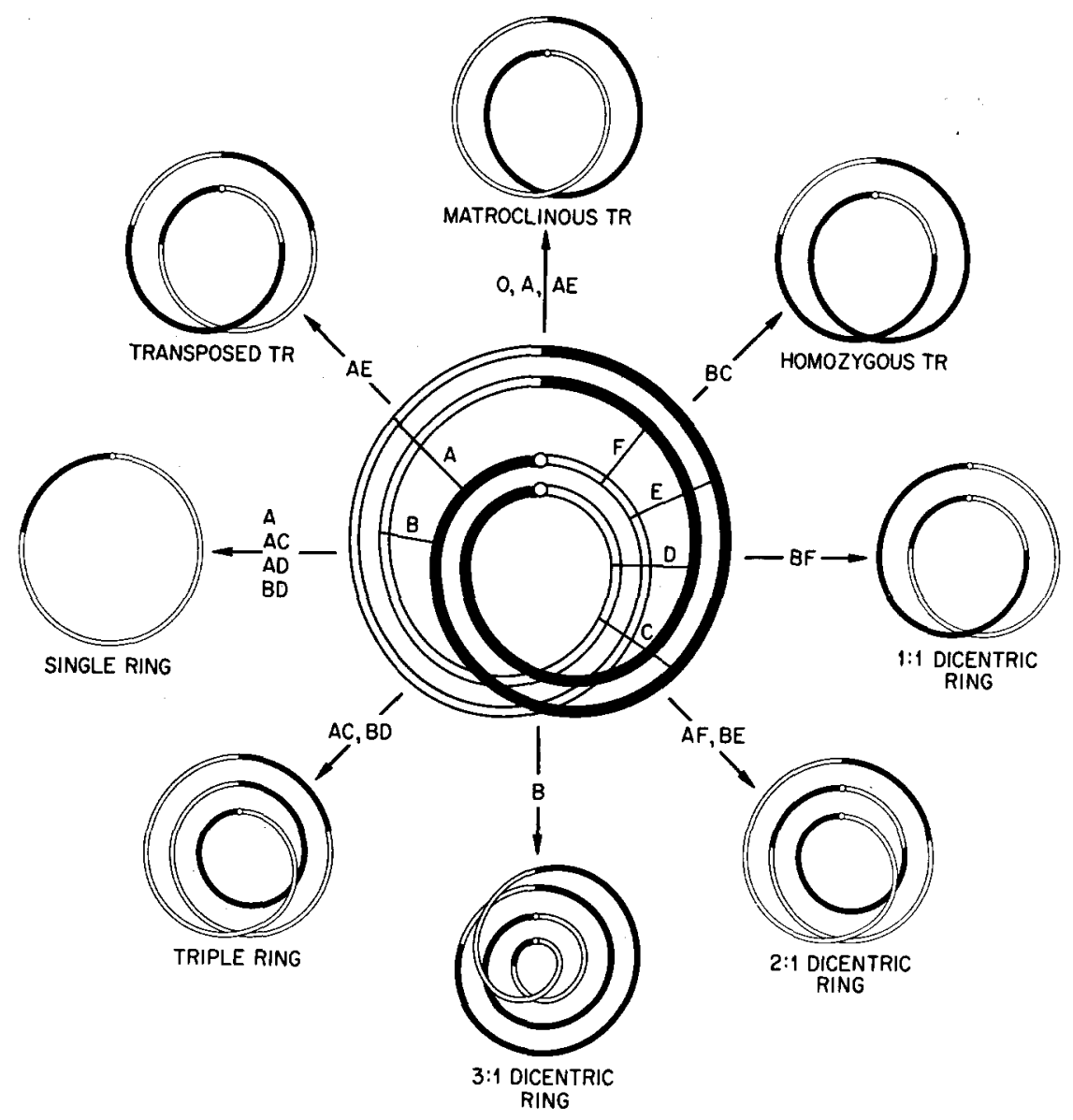

FigUre 3.-The centric meiotic products of tandem compound ring $\mathrm{X}$ chromosomes with no, single, and double exchange (assuming no sister-strand crossing over). The tetrad types from which each product may be derived are indicated.

Dicentric compound ring chromosomes are formed that contain 2,3 , or $4 \mathrm{X}$ chromosomes. The centromeres divide these rings into two segments, the first containing 1 and the other 1,2 , or $3 \mathrm{X}$ chromosomes. The dicentrics form double second-anaphase bridges, which are referred to as 1:1,2:1, and 3:1 double bridges. Sturtevant and Beadle (1936) considered second anaphase bridges to be lethal, but later Novitski (1955) postulated that whereas 2:1 and 3:1 double second anaphase bridges are lethal, the symetrical 1:1 bridges are excluded from the egg nucleus and give rise to exceptional patroclinous males. Our recent data, however, suggest that 1:1 double second anaphase bridges generated in tandem metacentric compounds are lethal (LiNDSLEY and SANDLER 1965).

The four products of meiosis in $\mathrm{C}(1) \mathrm{TR} / y^{+} \cdot \mathrm{Y}^{\mathrm{L}}$ females following the various types of exchange shown in Figure 3 are shown in the last four columns of Table 1. In column $2, E_{i}$ is the frequency of tetrads of rank $i$, in which $\sum_{i} E_{i}=1$; 


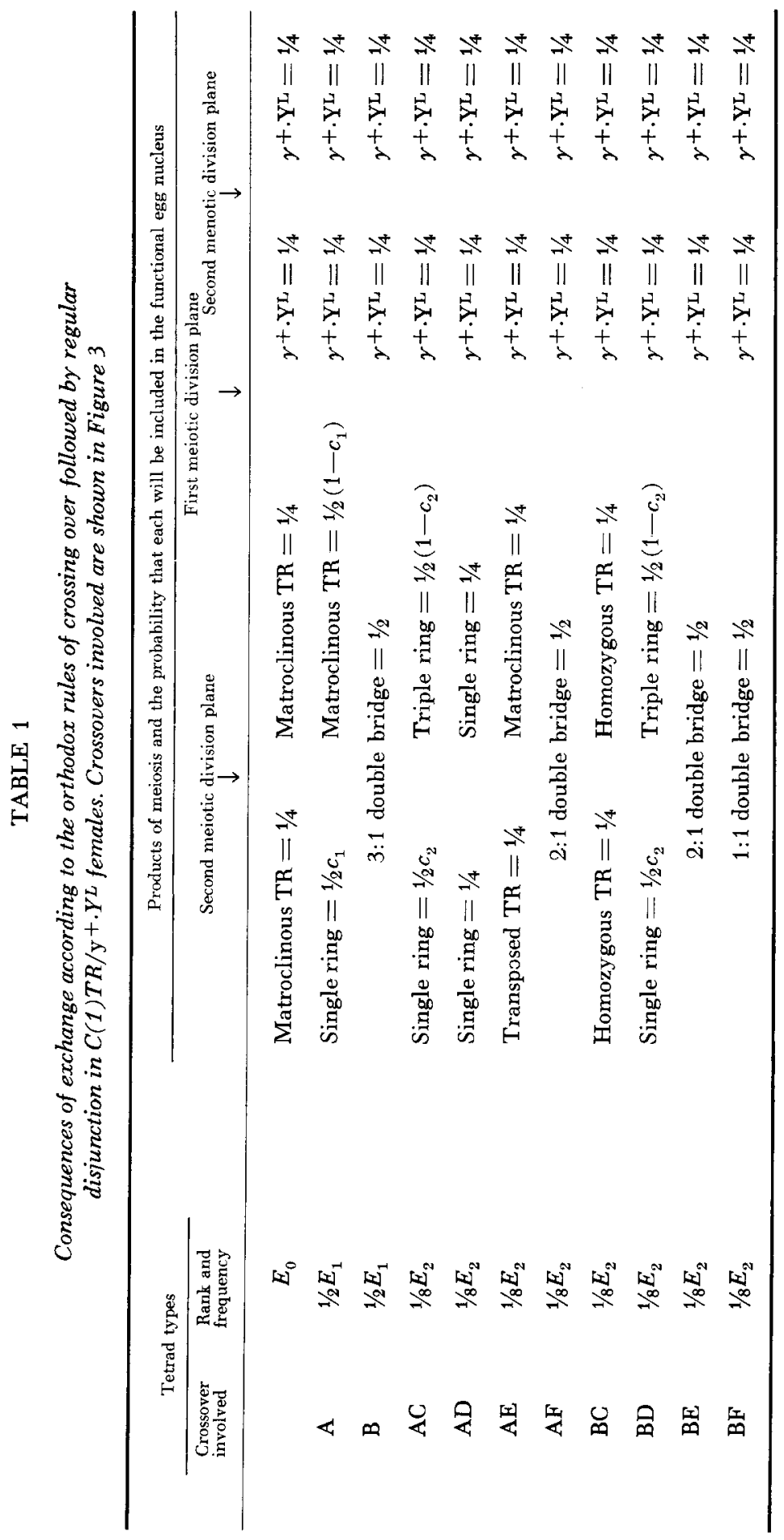




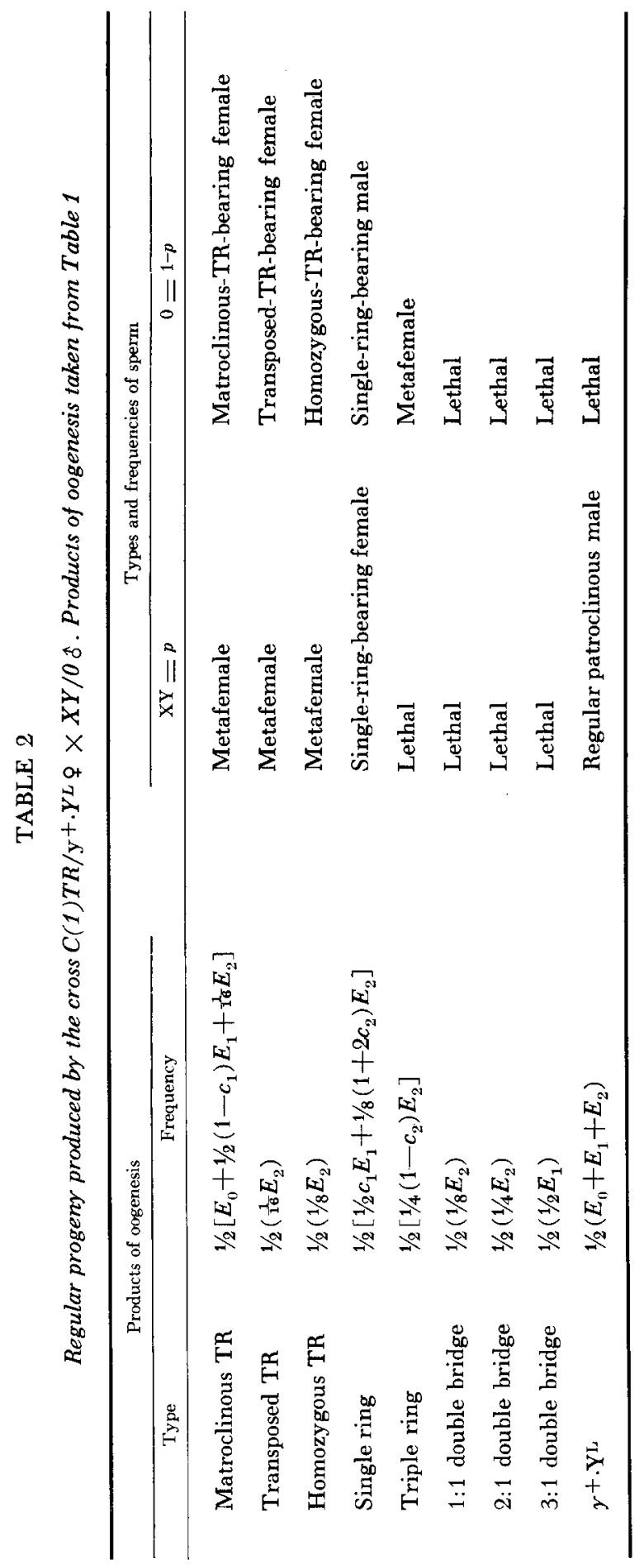


the coefficients of $E_{i}$ are based on the assumption that there is no strand preference and no chromatid interference. In columns 3 and 4, the parameter $c$ is the coefficient of nonrandomness (Novitski 1951); the probability of recovering a single ring in the functional egg nucleus is $c_{1}$ when the ring separates from a TR at second anaphase and $c_{2}$ when it separates from a triple ring. The unsplit TR centromere proceeds toward one pole at the first division, and all egg nuclei developing from that pole are considered presumptive $X$-bearing ova whether or not they contain an $\mathrm{X}$ chromosome (columns 3 and 4, Table 1). Similarly, egg nuclei developing from the other half of the first meiotic division (columns 5 and 6 , Table 1) are considered presumptive $Y$-bearing ova whether or not they carry $y^{+\cdot Y^{L}}$.

The terms in Table 1 are collected in Table 2 (columns 1 and 2) to yield expressions for the expected frequencies of the various types of ova produced by $\mathrm{C}$ (1) $\mathrm{TR} / y^{+} \cdot \mathrm{Y}^{\mathrm{L}}$ females. The types of zygotes produced when these ova are fertilized by sperm from $\mathrm{Y}^{\mathrm{s}} \mathrm{X} \cdot \mathrm{Y}^{\mathrm{L}} / 0(=\mathrm{XY} / 0)$ males are shown in columns 3 and 4 of Table 2 where $p$ and $1-p$ represent the frequencies of functional XY-bearing and nullo-XY sperm, respectively; $p$ may be estimated directly from the proportion of daughters among the progeny of normal females crossed to XY/0 males. If the data are corrected for any inequalities in the proportions of XY-bearing and nullo-XY sperm by multiplying by $p /(1-p)$ the numbers of flies observed in classes resulting from fertilization with nullo-XY sperm, then the expression for each zygotic class is a function of $E_{i}, c_{1}$, and $c_{2}$ multiplied by $1 / 2 p$. Considering ratios of classes or groups of classes leads to equations in $E_{i}, c_{1}$, and $c_{2}$ alone.

Sister-strand exchange: The expectations from the LINDEGREN-SCHwartz model of sister-strand exchange are developed in Figure 4 and Tables 3 and 4 in much the same way that the expectations based on standard assumptions are in Figure 3 and Tables 1 and 2.

The regions of a double ring for which the consequences of sister-strand exchange must be considered are those uninterrupted by a homologous exchange. In a no exchange tetrad the entire chromosome represents one such region. A single exchange involves two points on the circumference of the double ring (i.e., homologous points on the two component $\mathrm{X}$ chromosomes); thus in one exchange tetrads there are two regions of sister-strand exchange, each comprising half the circumference of the double ring. Each additional exchange subdivides two preexisting regions and thus increases the number of regions of sisterstrand exchange by two [in other words, the number of regions in which sisterstrand exchange must be considered is $2 i$ (where $i$ equals the rank of the tetrad) when $i>0$, and 1 when $i=0$ ].

A comparison of Figures 3 and 4 reveals that the two hypotheses predict identical arrays of monocentric products, but according to the sister-strand-exchange hypothesis, there will be one type of dicentric compound ring that is not among those expected from the orthodox model of exchange. This ring is composed of four X chromosomes and will produce a $2: 2$ double second anaphase bridge. Unfortunately, this ring is not a directly scorable product. The sister-strand exchange model also predicts a unique acentric (i.e., an acentric double ring) which is 


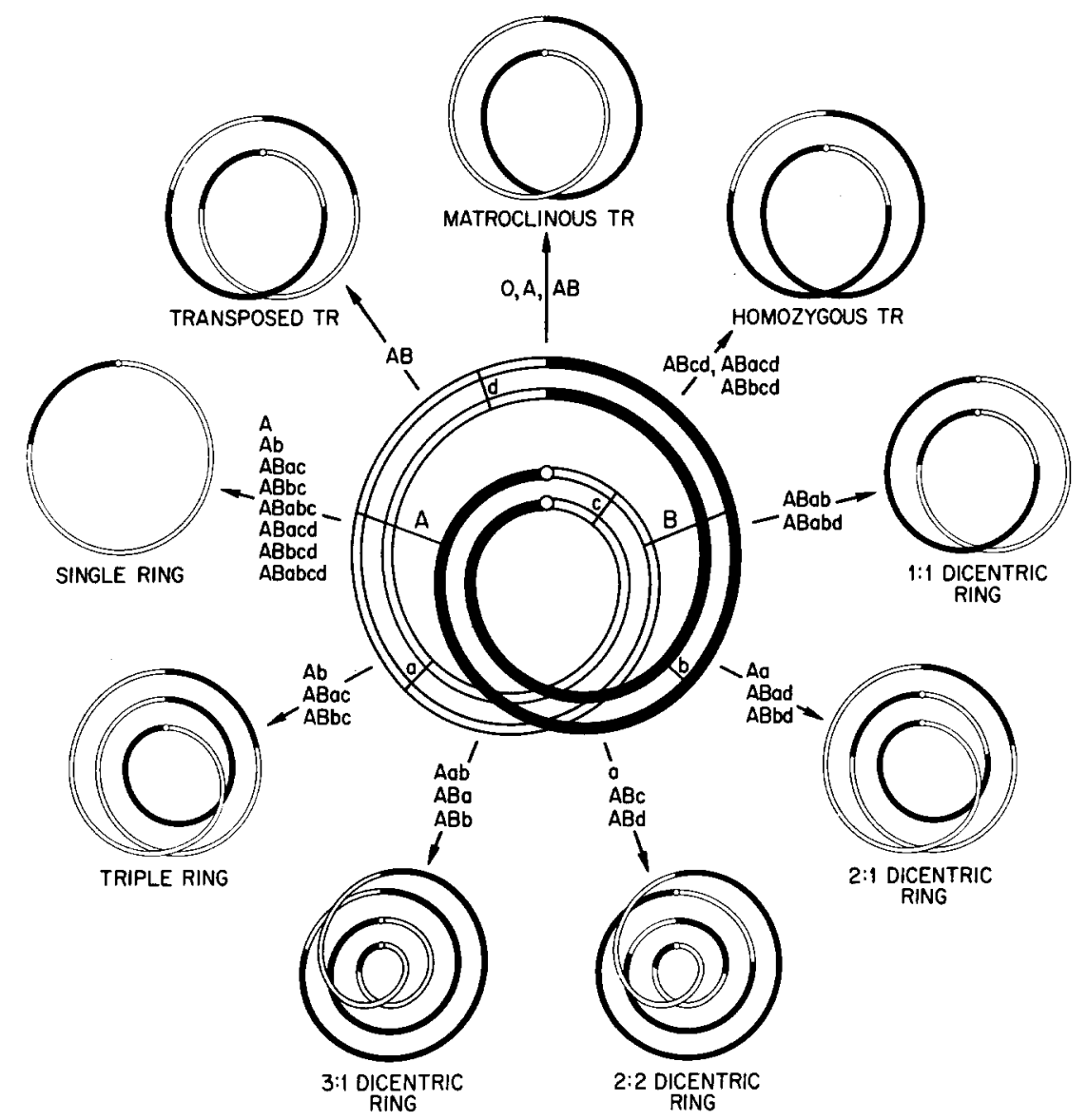

FIgURe 4,-The centric meiotic products of tandem compound ring $\mathrm{X}$ chromosomes with no, one, or two exchanges, according to the sister-strand crossing-over model described in the text. The tetrad types from which each product may be derived are indicated.

also unscorable. Thus, there are no qualitative differences in the scorable yield predicted from the two models. Examination of column 2 in Tables 2 and 4, however, shows that the expectations from the two models differ quantitatively. Tandem rings recoverable from presumptive $\mathrm{X}$-bearing ova are half as frequent from the sister-strand-exchange model as from the orthodox model. This difference provides a basis for discriminating between the two models.

\section{Differences Among Tandem Ring Lines}

A number of presumptive $\mathrm{C}(1) \mathrm{TR}$ derivatives from each $\mathrm{C}(1) \mathrm{TM} B^{\mathrm{s}}$ line were selected and crossed to $\mathrm{XY} / 0$ males; the results of these crosses are presented in Table 5. Although the progenies form a homogeneous sample with respect to the ratio of patroclinous males to single-ring-bearing progeny, the presumptive TRbearing females recovered from $\mathrm{C}(1) \mathrm{TM} B^{\mathrm{s}} 9-1$ differ from those recovered from 


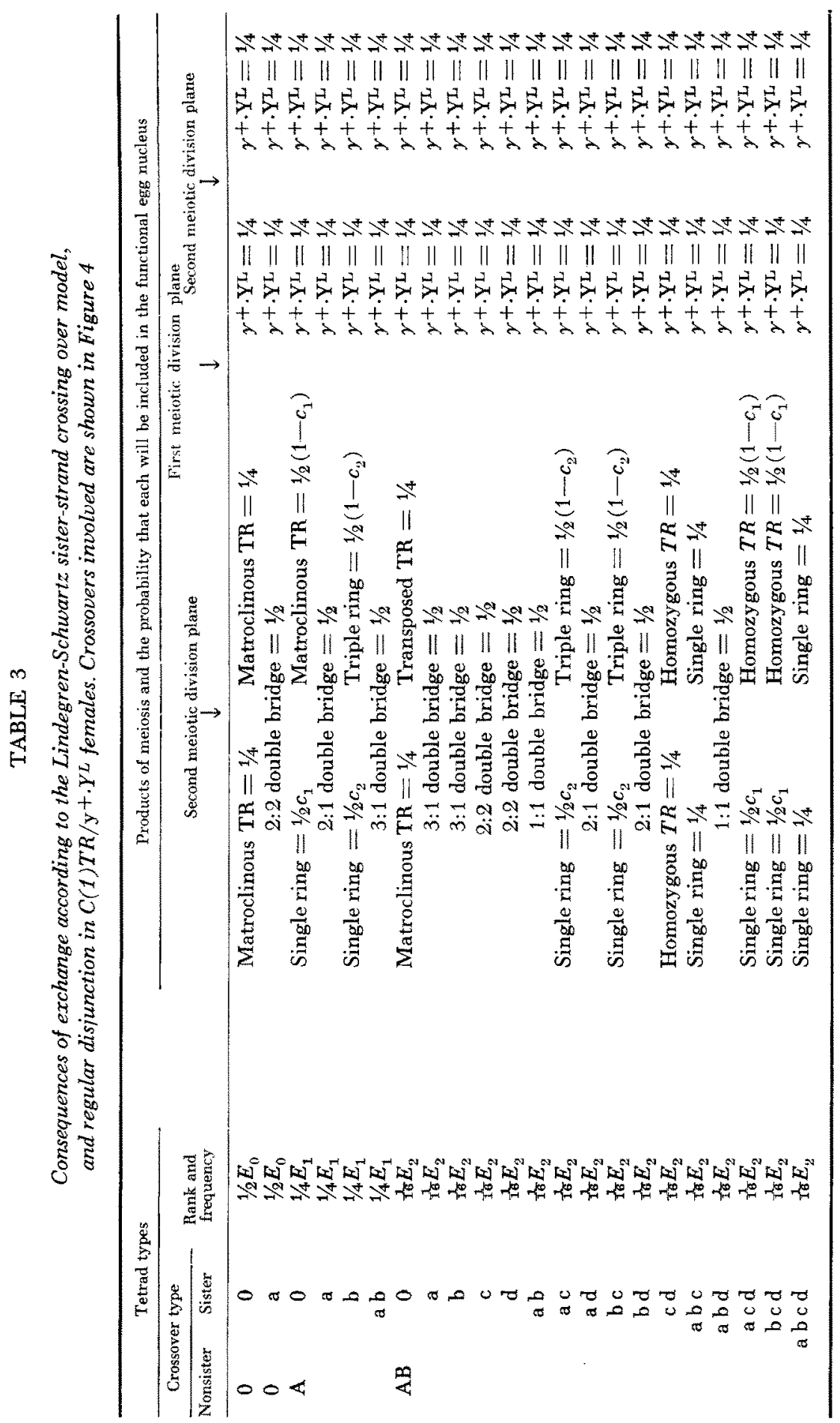




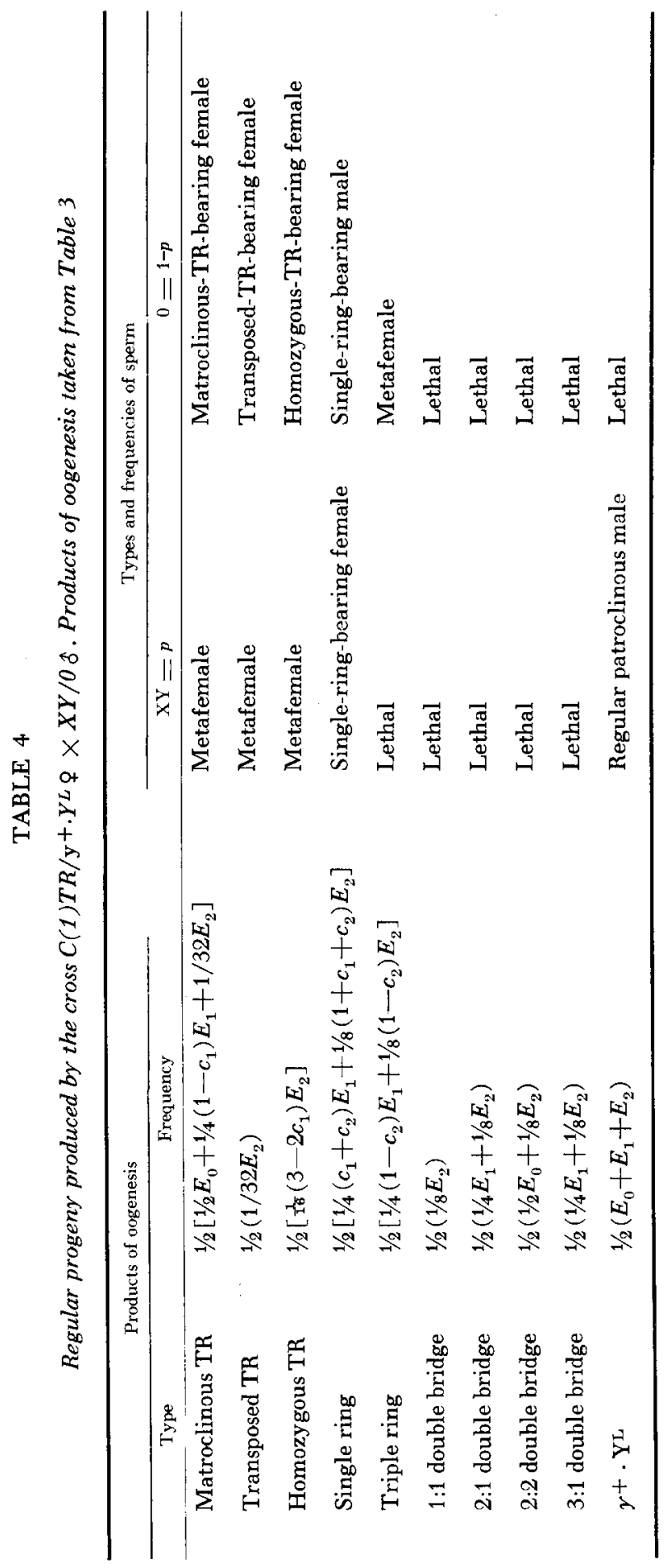


TABLE 5

Progeny produced by putative TR-bearing females (recovered from the cross $C(1) T M \mathrm{~B}^{S} / 0$ females $\times X Y, \mathrm{v}$ B B/O males) crossed with $X Y^{*} / 0$ males

\begin{tabular}{|c|c|c|c|c|c|c|}
\hline \multicolumn{2}{|c|}{ Parent } & \multicolumn{4}{|c|}{ Progeny } & \\
\hline & & \multirow[b]{2}{*}{$\begin{array}{l}\text { Patroclinous } \\
\text { mnales* }\end{array}$} & \multirow{2}{*}{$\underset{\substack{\text { TR-bearing } \\
\text { fenales }}}{\substack{y \\
\text { nat }}}$} & \multicolumn{2}{|c|}{ Single-ring-bearing } & \\
\hline $\begin{array}{l}\text { Source } \\
\text { TM } B^{*}\end{array}$ & $\begin{array}{l}\text { TR-bearing } \\
\text { female }\end{array}$ & & & $\begin{array}{c}\text { Females } \\
B / t\end{array}$ & $\begin{array}{c}\text { Males } \\
y\end{array}$ & \\
\hline \multirow[t]{10}{*}{$9-1$} & $91-1$ & 39 & 0 & 8 & 7 & \\
\hline & $91-2$ & 43 & 0 & 9 & 5 & \\
\hline & $91-3$ & 20 & 0 & 3 & 4 & \\
\hline & $91-4$ & 26 & 1 & 6 & 4 & \\
\hline & $91-41 \dagger$ & 17 & 0 & 2 & 2 & \\
\hline & $91-6$ & 9 & 0 & 5 & 1 & \\
\hline & $91-7$ & 6 & 0 & 1 & 3 & \\
\hline & $91-9$ & 5 & 0 & 4 & 4 & - \\
\hline & $91-11$ & 18 & 0 & 11 & 9 & \\
\hline & $91-12$ & 20 & 0 & 5 & 1 & \\
\hline \multirow[t]{11}{*}{$9-4$} & $94-1$ & 118 & 30 & 31 & 29 & \\
\hline & $94-2$ & 135 & 12 & 37 & 23 & \\
\hline & $94-3$ & 69 & 0 & 13 & 15 & \\
\hline & $94-4$ & 4 & 0 & 0 & 0 & \\
\hline & $94-5$ & 6 & 0 & 0 & 4 & \\
\hline & $94-6$ & 108 & 0 & 35 & 41 & \\
\hline & $94-7$ & 75 & 3 & 12 & 9 & \\
\hline & $94-8$ & 112 & 2 & 37 & 25 & \\
\hline & $94-9$ & 106 & 17 & 22 & 21 & \\
\hline & $94-10$ & 61 & 1 & 25 & 10 & \\
\hline & $94-11$ & 64 & 16 & 18 & 14 & \\
\hline
\end{tabular}

* $y$ for 9-1 derivatives and $\nu f B$ for 9-4 derivatives.

$\rightarrow$ The $y$ daughter of female $91-4$.

$\mathrm{C}$ (1) TMB $B^{\mathrm{s}} 9-4$ in two respects: (1) the mean numbers of progeny produced by females carrying 9-1 and 9-4 derived TR's are 30 and 124, respectively; (2) only one among nine presumptive TR-bearing females from $\mathrm{C}(1) \mathrm{TM} B^{\mathrm{s} 9}-1$ (91-4) produced a TR-bearing daughter (914-1), and she in turn failed to transmit her TR, whereas seven out of 11 TR-bearing females from C(1)TMBs9-4 produced TR-bearing daughters; we chose to establish lines from two of these progenies (94-1 and 94-2). In other words, the tandem ring-bearing females from the two lines differ in both fecundity and transmission of the TR.

In addition to the difference in transmissibility of TR's between TR-bearing females from $\mathrm{C}(1) \mathrm{TM} B^{\mathrm{s} 9-1}$ and 9-4, it can be seen that there is considerable variability among $\mathrm{C}(1)$ TR94-bearing females. This variability seems to be a property of the TR's derived from $\mathrm{C}(1) \mathrm{TM} B^{\mathrm{s} 9-4}$, because subsequent testing of the TR-bearing daughters of C(1)TR94-1 and C(1)TR94-2 exhibited similar variability (e.g., 10/25 daughters of female 94-1 failed to produce TR-bearing daughters). Lines do, however, seem to become more uniform with successive generations.

$C$ (1) $\mathrm{TM} B^{\mathrm{s}} 9-1$ is characterized by a low incidence of TR generation, and the 
TR-bearing females which are generated very rarely transmit a TR to their progeny. These two observations are probably manifestations of the same phenomenon (i.e., the reduced transmissibility of TR chromosomes derived from $C$ (1) $T M B^{s 9-1}$ whether they are newly generated or preexisting). The tandem rings from $\mathrm{C}$ (1) $\mathrm{TM} B^{\mathrm{s}} 9-4$, on the other hand, exhibit a higher transmission both as newly generated and as preexisting chromosomes. This behavior difference between tandem rings from $\mathrm{C}(1) \mathrm{TM} B^{s} 9-1$ and $\mathrm{C}(1) \mathrm{TM} B^{s} 9-4$ must be attributed to differences in the structure of the two tandem-ring-generating metacentric chromosomes. These two chromosomes are identical in structure except that at the base of the arm in normal sequence $\mathrm{C}(1) \mathrm{TM} B^{\mathrm{s}}$-1 has almost twice as much heterochromatin as C(1)TMBs9-4 (LindsLey and SANDLER 1965). This heterochromatic segment is invariably included in newly generated TR's, and the extra pericentric heterochromatin in C (1) TM $B^{s 9}$-1 must be responsible in some way for the lower recovery of the TR's produced; it does not, however, appear to affect the recovery of single ring derivatives of either $\mathrm{C}(1) \mathrm{TM} B^{s} 9-1$ or its derivative tandem ring (see Table 5, and LindsLey and SANDLER 1965, Table 12). The cause of the lower fecundity of TR females from C(1) TMBs $B^{s}-1$ compared with those from $\mathrm{C}(1) \mathrm{TM} B^{s} 9-4$ must also reside in this increment of heterochromatin. Moreover, since these two tandem metacentrics are themselves regularly transmitted (LiNDSLEX and SANDLER 1965), it may be concluded that the differences in transmissibility between the tandem rings are due to structural differences that are important only when the chromosome is a ring.

There are now data from three independent constructions of TR chromosomes, those from $\mathrm{C}(1) \mathrm{TM} B^{s} 9-1, \mathrm{C}(1) \mathrm{TM} B^{s} 9-4$, and $\mathrm{C}(1) \mathrm{TR}$ made by NovitskI (1954) from a tandem acrocentric compound $\mathrm{X}$ chromosome with $\mathrm{Y}^{\mathrm{L}}$ as a second arm by attaching the free end of the compound and the second arm. The results of crosses of C(1)TR/0 females carrying each of these TR's are given in Table 6. It can be seen that although the proportion of single-ring $\mathrm{X}$ chromosomes recovered is about the same for all three lines, the recovery of compound-bearing females is highest $(16 \%)$ in TR's from $\mathrm{C}(1) \mathrm{TM} B^{\mathrm{s}} 9-4$, considerably lower for Novirski's TR (9\%), and even lower for TR's from C(1) TM $B^{s} 9-1$ (1\%). Thus,

TABLE 6

Comparison of the results from crosses of females carrying tandem compound ring $X$ chromasomes of different origins. The cross, in all cases, is: $C(1) T R / 0$ females $\times X Y / 0$ males

\begin{tabular}{|c|c|c|c|c|c|c|}
\hline \multirow[b]{2}{*}{ Class of progeny } & \multicolumn{6}{|c|}{ Source of TR } \\
\hline & \multicolumn{2}{|c|}{$\begin{array}{l}\text { C(1) } \\
\text { No. } \\
\text { Percent }\end{array}$} & \multicolumn{2}{|c|}{$\begin{array}{l}\mathrm{C}(1) \mathrm{TM} B^{s 9} 9-4 \dagger \\
\text { No. Percent }\end{array}$} & \multicolumn{2}{|c|}{$\begin{array}{l}C(1) T M B^{s 9-1 \ddagger} \\
\text { No. Percent }\end{array}$} \\
\hline Patroclinous males & 8224 & 100 & 15912 & 100 & 203 & 100 \\
\hline Matroclinous-TR bearing females & 735 & 9 & 2611 & 16 & 1 & 1 \\
\hline Single-ring-bearing females & 1844 & 22 & 3404 & 21 & 54 & 27 \\
\hline Single-ring-bearing males & 2095 & 25 & 1675 & 11 & 40 & 20 \\
\hline
\end{tabular}

- The details of the origin of this TR and the data are given in Novirsk (1954).

+ The data are given in exterso in Table 8 .

\$ The data are summed from Table 5 . 
NovitskI's tandem ring has a transmissibility which is intermediate between those of $\mathrm{C}(1) \mathrm{TM} B^{\mathrm{s} 9}-1$ and $\mathrm{C}(1) \mathrm{TM} B^{\mathrm{s}} 9-4$.

\section{EXPERIMENTAL RESULTS}

Females carrying $\mathrm{C}(1) \mathrm{TR}, \operatorname{In}(1) E N \cdot+, y s n g \cdot y$ cv $v$ sd were crossed with $\mathrm{Y}^{\mathrm{s} X} \cdot \mathrm{Y}^{\mathrm{L}}, \operatorname{In}(1) E N, y B / 0$ males. The results of these crosses are presented for $\mathrm{C}$ (1) TR $/ y^{+} \cdot \mathrm{Y}^{\mathbf{L}}$ in Table 7 and for $\mathrm{C}(1) \mathrm{TR} / 0$ in Table 8. Because the markers carried by the single rings indicate unambiguously the phase of the markers in the maternal TR, we were able, without bias, to confine our attention to rings marked as indicated above (see also Figure 1).

\section{TABLE 7}

Results from cross $C(1) T R, \operatorname{In}(1) \mathrm{En} \cdot+, \mathrm{y} \mathrm{sn} \mathrm{g} \cdot \mathrm{y} \mathrm{cv} \mathrm{v} \mathrm{sd} / \mathrm{y}+\cdot Y^{L}$ females $\times Y^{S} X \cdot Y^{L}, \operatorname{In}(1) \mathrm{EN}$, y $\mathrm{B} / 0$ males

\begin{tabular}{|c|c|c|c|}
\hline \multirow[b]{2}{*}{ Class of progeny } & \multirow[b]{2}{*}{ Phenotype } & \multicolumn{2}{|c|}{ Observed number } \\
\hline & & $94-1$ & $94-2$ \\
\hline Regular patroclinous males & $B$ & 5006 & 2830 \\
\hline Exceptional patroclinous males & $y B$ & 734 & 393 \\
\hline Regular nonhomozygous-TR-bearing females & $r$ & 947 & 483 \\
\hline Exceptional nonhomozygous-TR-bearing females & + & 4 & 1 \\
\hline Regular homozygous-TR-bearing females & $\begin{array}{c}y c v \\
y v \\
y s d \\
y c v v \\
y v s d \\
y c v v s d \\
y s n \\
y g \\
y s n g\end{array}$ & $\begin{array}{r}5 \\
20 \\
1 \\
14 \\
11 \\
5 \\
11 \\
20 \\
18\end{array}$ & $\begin{array}{r}0 \\
8 \\
4 \\
10 \\
9 \\
2 \\
9 \\
10 \\
13\end{array}$ \\
\hline Regular single-ring-bearing females & $y B / y+$ & 1857 & 1235 \\
\hline Exceptional ring-bearing females & $B /+$ & 1 & 3 \\
\hline Regular single-crossover-single-ring-bearing males & $\begin{array}{c}y c v v s d \\
y v s d \\
y s n v s d \\
y s n s d \\
y s n g s d \\
y s n g\end{array}$ & $\begin{array}{l}271 \\
269 \\
370 \\
304 \\
163 \\
279\end{array}$ & $\begin{array}{l}155 \\
127 \\
231 \\
184 \\
123 \\
193\end{array}$ \\
\hline Exceptional single-crossover-single-ring-bearing males & $\begin{array}{c}s n v s d \\
\text { sn sd }\end{array}$ & $\begin{array}{l}1 \\
2\end{array}$ & $\begin{array}{l}0 \\
0\end{array}$ \\
\hline Regular-triple-crossover-single-ring-bearing males & $\begin{array}{c}y c v g \\
y s d\end{array}$ & $\begin{array}{l}0 \\
1\end{array}$ & $\begin{array}{l}1 \\
0\end{array}$ \\
\hline Exceptional triple-crossover-single-ring-bearing males & $\begin{array}{l}c v g \\
\operatorname{sn} v\end{array}$ & $\begin{array}{l}1 \\
3\end{array}$ & $\begin{array}{l}0 \\
0\end{array}$ \\
\hline
\end{tabular}


TABLE 8

Results of the crass $C(1) T R, \operatorname{In}(1) \mathrm{EN} \cdot+, \mathrm{y}$ sn $\mathrm{g} \cdot \mathrm{y} \mathrm{cv} v \mathrm{sd} / 0$ females $\times Y^{S} X \cdot Y^{L}, \operatorname{In}(1) \mathrm{EN}$, y B/O males

\begin{tabular}{|c|c|c|c|}
\hline \multirow[b]{2}{*}{ Class of progeny } & \multirow[b]{2}{*}{ Phenotype } & \multicolumn{2}{|c|}{ Observed number } \\
\hline & & $94-1$ & $94-2$ \\
\hline Patroclinous males & $y B$ & 7363 & 8549 \\
\hline Nonhomozygous-TR-bearing females & $r$ & 1553 & 944 \\
\hline \multirow[t]{9}{*}{ Homozygous-TR-bearing females } & $y c v$ & 0 & 0 \\
\hline & $\gamma v$ & 16 & 11 \\
\hline & $y s d$ & 7 & 2 \\
\hline & $y c v v$ & 8 & 6 \\
\hline & $y v s d$ & 6 & 5 \\
\hline & $y c v v s d$ & 5 & 3 \\
\hline & $y s n$ & 5 & 2 \\
\hline & $y g$ & 13 & 15 \\
\hline & $y \sin g$ & 6 & 4 \\
\hline Single-ring-bearing females & $y B / y+$ & 2099 & 1305 \\
\hline \multirow[t]{6}{*}{ Single-crossover-single-ring-bearing males } & $y c v v s d$ & 128 & 92 \\
\hline & $y v s d$ & 147 & 91 \\
\hline & $y \operatorname{sn} v s d$ & 176 & 121 \\
\hline & $\gamma s n s d$ & 203 & 135 \\
\hline & $y \operatorname{sng} s d$ & 95 & 74 \\
\hline & $y \sin g$ & 221 & 192 \\
\hline \multirow[t]{4}{*}{ Triple-crossover-single-ring-bearing-males } & $y c v v$ & 1 & $\mathbf{0}$ \\
\hline & $y v$ & 1 & 0 \\
\hline & $y g$ & 2 & $\mathbf{0}$ \\
\hline & $\gamma s d$ & 0 & 1 \\
\hline Other males & $y$ & 0 & 4 \\
\hline
\end{tabular}

Additional classes of progeny: Several classes of progeny that were not discussed in the section on expected behavior of tandem rings appear in Tables 7 and 8. Both tables include small numbers of single rings resulting from triple exchange. Because tetrads of rank greater than two represent less than two percent of all tetrads, they are not considered in the analysis of the results, and triple exchange single rings are pooled with single exchange rings in our computations. The progenies of $\mathrm{C}(1) \mathrm{TR} / y^{+} \cdot \mathrm{Y}^{\mathrm{L}}$ mothers contain some exceptions. Primary nondisjunction of the TR from $y^{+} \cdot \mathrm{Y}^{\mathrm{L}}$ produces disomic exceptional ova that contain the TR or its single ring derivative and $y^{+} \cdot \mathrm{Y}^{\mathrm{L}}$, and nullosomic exceptional ova, which contain no sex chromosome element. $\mathrm{C}(1) \mathrm{TR} / y^{+} \cdot \mathrm{Y}^{\mathrm{L}}$ ova produce scorable progeny when fertilized by nullo-XY sperm as do $\mathrm{R}(1) / y^{+} \cdot \mathrm{Y}^{\mathrm{L}}$ ova when fertilized by either XY-bearing or nullo-XY sperm. The resulting exceptional progeny are extremely rare. Nullosomic exceptional ova produce exceptional patroclinous males when fertilized by XY-bearing sperm. Exceptional progeny derived from the disomic and nullosomic products of primary nondisjunction should occur with comparable frequencies, but as shown in Table 7, the number of exceptional patroclinous males recorded is immense compared to the other exceptional classes. 
Additional sources of exceptional patroclinous males will be considered in the analysis of the data.

It may be noted in Table 7 that among triple crossover single-ring-bearing progeny, the majority are primary exceptions. Since disomic exceptions are extremely rare among all other classes of progeny, we presume that these particular cases arose from unpredicted events rather than from the simultaneous occurrence of two rare but predicted events (e.g., the $c v \mathrm{~g}$ male could be a recombinant between $y^{+\cdot Y^{L}}$ and the acentric ring formed by exchange between $s n$ and $v)$.

Finally, the four $y$ males recovered from C(1)TR94-2/0 and listed at the end of Table 8 were found among the progeny of a single cross, and they probably represent a cluster of patroclinous males with a $B$ reversal.

Estimation of sperm frequencies: In the analysis of the data from Tables 7 and 8 , we must consider the frequency of ova fertilized by $\mathrm{XY}$-bearing and nullo- $\mathrm{XY}$ sperm. It has been shown that the nullo-XY sperm production by $\mathrm{Y}^{\mathrm{s}} \mathrm{X} \cdot \mathrm{Y}^{\mathrm{L}} / 0$ males is in excess of that by $\mathrm{Y}^{\mathrm{S} X} \cdot \mathrm{Y}^{\mathrm{L}} / y^{+} \cdot \mathrm{Y}^{\mathrm{L}}$ males (SANDLER and Braver 1954), so that in crosses using $\mathrm{Y}^{\mathrm{s} X} \cdot \mathrm{Y}^{\mathrm{L}} / 0$ males, classes resulting from fertilization by $\mathrm{XY}$ bearing sperm are conventionally corrected upward. However, when sister females carrying either $\mathrm{C}$ (1) TR94-1 or C(1) TR94-2 were crossed with $\mathrm{Y}^{\mathrm{s}} \mathrm{X} \cdot \mathrm{Y}^{\mathrm{L}}$, $\operatorname{In}(1) E N, y B / y^{+\cdot \mathrm{Y}^{\mathrm{L}}}$ and $\mathrm{Y}^{\mathrm{s} X} \cdot \mathrm{Y}^{\mathrm{L}}, \operatorname{In}(1) E N, y B / 0$ males, the recovery of singlering-bearing progeny was 344 females to 351 males in $\mathrm{XY} / y^{+} \cdot \mathrm{Y}^{\mathrm{L}}$ crosses and 114 females to 110 males in $\mathrm{XY} / 0$ crosses. These results, coupled with those of Lindsley and Sandeer (1965) and Merriam (personal communication) obtained at the same time on the same $\mathrm{Y}^{\mathrm{s} X} \cdot \mathrm{Y}^{\mathrm{L}}, \operatorname{In}(1) E N, y B$ stock, indicate that $\mathrm{XY}$-bearing and nullo-XY sperm function with equal frequency in the crosses summarized in Tables 7 and 8 ; therefore, no correction need be made.

Measurements of recombination: In this section we will consider the reliability of the observed frequencies of the various types of progeny produced by TRbearing females. First, it seems that the observed frequency of homozygosis is very close to the total frequency. This follows from the facts that (1) the arrangement of markers (Figure 1) is such that any TR simultaneously homozygous for more than one recessive allele has a TR homozygous for at least one recessive allele as a complementary product, either of the same exchange or of a complementary one, (2) progeny tests of females homozygous for single markers from an identically marked tandem metacentric chromosome indicate that about $95 \%$ of them have a complementary product homozygous for at least one recessive allele (see Table 7 in LindsLey and SAndLer 1965), and (3) the distribution of crossing over in tandem rings (the crossover distances are almost identical with those of the similarly marked tandem metacentrics given in Figure 6 in Lindsley and SANDLer 1965) is such as to suggest that few, if any, double crossovers are missed entirely.

A second point to note is that the relative viability of the single-ring-bearing classes is the same as that of the patroclinous male class. This can be shown as follows: females heterozygous for $\ln (1) d l-49, y w B$ and either $\mathrm{Y}^{\mathrm{s} X} \cdot \mathrm{Y}^{\mathrm{L}}$, $\operatorname{In}(1) E N, y B$ or $\mathrm{R}(1) 94-1$ (the single ring derived from C(1)TR94-1) or 
$\mathrm{R}$ (1) 94-2 were crossed to $\mathrm{Y}^{\mathrm{s} X} \cdot \mathrm{Y}^{\mathrm{L}}, \operatorname{In}(1) E N, y B / y^{+} \cdot \mathrm{Y}^{\mathrm{L}}$ males. Each of these crosses produced $\ln (1) d l-49, y w B / y^{+} \cdot \mathrm{Y}^{\mathrm{L}}$ sons in addition to $\mathrm{Y}^{\mathrm{s}} \mathrm{X} \cdot \mathrm{Y}^{\mathrm{L}}, \operatorname{In}(1) E N$, $y B / y^{+} \cdot \mathrm{Y}^{\mathrm{L}}$, and $\mathrm{R}(1) 94-1 / y^{+} \cdot \mathrm{Y}^{\mathrm{L}}$ and $\mathrm{R}(1) 94-2 / y^{+} \cdot \mathrm{Y}^{\mathrm{L}}$ sons, respectively. The following ratios were observed: $\mathrm{XY} / y^{+\cdot \mathrm{Y}^{\mathrm{L}}}: \operatorname{In}(1) d l-49 / y^{+} \cdot \mathrm{Y}^{\mathrm{L}}=1230: 1577=$

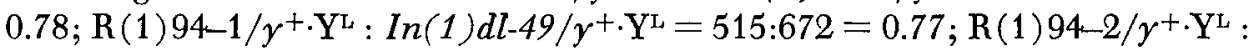
In(1) $d l-49 / y^{+} \cdot \mathrm{Y}^{\mathrm{L}}=912: 1149=0.79$. Similarly, the ratios of $\mathrm{R}(1) 94-1 / \mathrm{XY}$ daughters and $\mathrm{R}(1) 94-2 / \mathrm{XY}$ daughters to $\ln (1) d l-49 / y^{+} \cdot \mathrm{Y}^{\mathrm{L}}$ sons were $515: 672$ $=0.77$ and $965: 1149=0.84$. Because the ratios of XY-, R(1)94-1-, and R (1)94-2bearing sons or daughters to a common genotype were comparable, we can conclude that their relative viabilities are comparable and that the single ring classes require no viability correction.

Finally, there is one exchange product, the transposed tandem ring, that is not immediately scorable. A transposed TR is a nonhomozygous TR in which all the markers of its parental TR are present but in which their coupling relations have become changed. It is the product of reciprocal double exchange (i.e., exchange involving strands attached to the same centromere) and results from $1 / 16$ of the two-exchange tetrads. Transposition frequency may be determined by progeny tests of nonhomozygous-TR-bearing daughters, because the marker content of any three different single-ring derivatives of a TR heterozygous for known markers uniquely determines the phase of the markers (LINDSLEY and SANDLER 1965). Among 206 nonhomozygous-TR-bearing daughters of $\mathrm{C}(1) \mathrm{TR} / y^{+} \cdot \mathrm{Y}^{\perp}$ mothers, 16 carried transposed TR's; among 126 nonhomozygous-TR-bearing daughters of C(1) TR/0 mothers, four carried transposed TR's. We may thus ascertain from the ratio of homozygous to nonhomozygous TR's observed in Tables 7 and 8 that these samples of nonhomozygous-TR-bearing females corresponded to roughly 25 and 6 homozygous-TR-bearing females, respectively. Thus, the expected ratio of homozygous to transposed TR's of $2: 1$ (see Table 2) is approximately realized.

\section{Analysis of $C(1) T R / \mathrm{y}^{+} \cdot Y^{L}$ data}

A cursory examination of the TR data presented in Tables 7 and 8 reveals marked differences between the behavior of $\mathrm{C}(1) \mathrm{TR} / 0$ and $\mathrm{C}(1) \mathrm{TR} / y^{+\cdot \mathrm{Y}^{\mathrm{L}}}$ females. In the absence of the homolog, the following occur: (1) the reduced frequencies of both homozygosis and transposition indicate reduced exchange values; (2) C (1) TR94-1 and C(1) TR94-2 behave differently from each other as to the relative frequencies of recovered compound-bearing females; single-ringbearing females and single-ring-bearing males; (3) both lines show reduced single ring recovery in comparison to the $\mathrm{C}(1) \mathrm{TR} / y^{+} \cdot \mathrm{Y}^{\mathrm{L}}$ results; and finally, (4) nullo-X presumptive $\mathrm{X}$-bearing ova are not distinguishable from the presumptive Y-bearing ova. For these four reasons, we confine our initial analysis to the data from $\mathrm{C}(1) \mathrm{TR} / \boldsymbol{y}^{+} \cdot \mathrm{Y}^{\mathrm{L}}$ females (Table 7).

It is instructive to consider first a tetrad analysis performed perhaps crudely but simply. We examine the data in Table 7, summed over the two compounds; we consider only single rings recovered in females; we ignore all of the exceptional classes; and to further simplify, we suppose (as experience indicates is 
approximately true) that both coefficients of nonrandom disjunction are equal to unity (i.e., $c_{1}=c_{2}=1$ in the equations given earlier). Thus, there were 171 homozygous females observed, which means (because homozygous $\mathrm{TR}=1 / 8 E_{2}$ ) that there were $8 \times 171=1368$ presumptive $\mathrm{X}$-bearing ova derived from oocytes with two-exchange tetrads; these were distributed among 171 homozygous TR's, 171 nonhomozygous TR's, 513 single rings, and 513 double second-anaphase bridges. The remaining 2579 single-ring-bearing females (the 3092 observed less the 513 from two-exchange tetrads) represent $1 / 2 E_{1}$; consequently, there were $2 \times 2579=5158$ presumptive X-bearing ova derived from oocytes with oneexchange tetrads, 2579 single rings and 2579 double second-anaphase bridges. Finally, there were 1259 nonhomozygous-TR-bearing females (i.e., the observed 1430 less the 171 products of two-exchange tetrads), which represent all the presumptive $\mathrm{X}$-bearing ova from oocytes with no-exchange tetrads. Since there is a presumptive Y-bearing ovum for every presumptive X-bearing ovum, the 7785 presumptive $\mathrm{X}$-bearing ova enumerated above (1368 from $E_{2}, 5158$ from $E_{1}$, and 1259 from $E_{0}$ ) imply that there were 7785 presumptive Y-bearing ova, which should have been recovered as regular patroclinous males; 7836 were actually observed. These calculations lead to the following estimated tetrad distribution: $E_{0}=0.16, E_{1}=0.66, E_{2}=0.18$. Thus, from the surviving products of presumptive $\mathrm{X}$-bearing ova we are able to predict almost exactly the observed number of presumptive Y-bearing ova. The above procedure amounts to estimating the number of presumptive $\mathrm{X}$-bearing ova from the following sum: nonhomozygous $\mathrm{TR}+7$ times homozygous $\mathrm{TR}+\left[\left(1+c_{1}\right) / c_{1}\right]$ times [single-ring female $\left(1+2 c_{2}\right)$ times homozygous TR].

Thus, the most striking feature about this analysis is that it accounts for all the eggs in the experiment. That is - supposing as we must that (1) the regular patroclinous male class, which is produced by $y^{+\cdot} \cdot \mathrm{Y}^{\mathrm{L}}$-bearing eggs fertilized by $\mathrm{XY}$-bearing sperm, gives a measure of the number of presumptive X-bearing ova and (2) that there is no strand preference or chromatid interference-the recovered products of the TR represent all the products there were. Furthermore, since there is no room to correct any of the surviving classes upward without causing the estimated number of presumptive X-bearing ova to exceed the observed number of presumptive Y-bearing ova, there is evidently no loss of theoretically recoverable products from the TR from either inviability or special difficulties caused by the complexity of the chromosome configuration, such as the formation of mutually interlocked complexes leading to lethality. Thus, the 1127 observed exceptional patroclinous males cannot be derived from theoretically recoverable classes, and we can therefore conclude that they come from oocytes with double second anaphase bridges, of which there were an estimated 3092 in these experiments.

It should also be noted that any significant change in the assumption that $c_{1}=c_{2}=1$ would increase the estimated number of presumptive X-bearing ova and would cause it to exceed the observed number of presumptive $Y$-bearing ova.

Novitskx (1955) pointed out that tandem rings are of special interest with respect to the existence and genetic consequences of interlocked ring complexes 
formed at meiosis, because several types of interlocked complexes are possible products from tandem rings, including some involving acentric rings (see Figure 3). He showed, however, that interlocking, if it occurred at all, has little genetic consequence. The results of this paper also show that interlocked complexes with genetic consequences do not occur with an appreciable frequency in tandem rings. It must be, therefore, that tandem rings possess some mechanism that prevents interlocked complexes from forming or that resolves them once formed.

Assuming that (1) the equations in Table 2 appropriately describe the behavior of tandem rings, (2) the exceptional patroclinous male class is derived from a fraction of the double second anaphase bridge classes (i.e., they do not enter into the calculation), and (3) no viability corrections are necessary, we performed tetrad analyses by automatic computer for C(1) TR94-1 and C(1)TR94-2 separately. The results are given in Table 9. Here we can see that except for minor differences, the two TR lines behave alike and have an exchange distribution close to that reported for the structurally similar tandem metacentric compound $\mathrm{X}$ chromosome (i.e., $E_{0}=0.18, E_{1}=0.48, E_{2}=0.33$; LINDSLEy and SANDLER 1965), with $c$ values approaching unity as they also do in the case of the tandem metacentric and the tandem acrocentric compounds. Thus, it appears that when a newly generated single $\mathrm{X}$ chromosome separates from a tandem compound $\mathrm{X}$ chromosome at second anaphase, the probability of recovering the single $\mathrm{X}$ is generally very close (or exactly equal) to unity.

The analysis up to this point has been done according to the conventional rules of crossing over (i.e., no strand preference, no chromatid interference, and no sister-strand crossing over). We may now consider whether the data are also consistent with the LINDEGREN-SCHWARTz model of crossing over.

We can proceed here most simply by noting in the equations given in Table 4

TABLE 9

The exchange distribution in $C(1) T R$ chromosomes tested in $C(1) T R / y+. Y^{L}$ females

\begin{tabular}{|c|c|c|c|c|}
\hline \multirow[b]{3}{*}{ Class of progeny } & \multicolumn{4}{|c|}{ TR line } \\
\hline & \multicolumn{2}{|c|}{$94-1$} & \multicolumn{2}{|c|}{$94-2$} \\
\hline & Observed & Expected ${ }^{*}$ & Observed & Expected* \\
\hline Regular patroclinous males & 5006 & 5004 & 2830 & 2888 \\
\hline Nonhomozygous-TR-bearing females & 951 & 950 & 484 & 453 \\
\hline Homozygous-TR-bearing females & 105 & 110 & 64 & 89 \\
\hline Single-ring-bearing males & 1664 & 1163 & 1014 & 1051 \\
\hline Single-ring-bearing females & 1860 & 1857 & 1238 & 1148 \\
\hline$c_{1}$ & \multicolumn{2}{|c|}{0.94} & \multicolumn{2}{|c|}{1.00} \\
\hline$c_{2}$ & \multicolumn{2}{|c|}{0.97} & \multicolumn{2}{|c|}{1.00} \\
\hline$E_{0}$ & \multicolumn{2}{|c|}{0.17} & \multicolumn{2}{|c|}{0.14} \\
\hline$E_{1}$ & \multicolumn{2}{|c|}{0.63} & \multicolumn{2}{|c|}{0.59} \\
\hline$E_{2}$ & \multicolumn{2}{|c|}{0.20} & \multicolumn{2}{|c|}{0.27} \\
\hline
\end{tabular}

* These are least squares expectations computed by machine for the equations and data given in Tables 2 and 7 . The exceptional patroclinous males were not considered. All parameters were constrained to values between 0 and $1 ; \Sigma E_{i}$ was unity; $c_{1}, c_{2}, E_{1}, E_{2}$, and $p$ (the frequency of XY-bearing sperm, which did not depart greatly from 0.5 ) were estimated. 
that according to the sister-strand-crossing over model, the sum $(V)$ of all the viable types derived from presumptive $\mathrm{X}$-bearing ova is

$$
V=1 / 2 E_{0}+1 / 4 E_{1}+3 / 8 E_{2}+c_{2}\left(1 / 4 E_{1}+1 / 8 E_{2}\right) \text {, }
$$

while that of the lethal classes, $L$, is

Thus, the difference

$$
L=1 / 2 E_{0}+3 / 4 E_{1}+5 / 8 E_{2}-c_{2}\left(1 / 4 E_{1}+1 / 8 E_{2}\right) \text {. }
$$

$$
L-V=\left(1 / 2 E_{1}+1 / 4 E_{2}\right)\left(1-c_{2}\right),
$$

which will be 0 when $c_{2}=1$ or $E_{1}=E_{2}=0$, and otherwise positive. In other words, the viable classes must always be equal to or less than the lethals. However, from Table 7 it can be seen that the viable classes exceed the lethals, or regular patroclinous males minus the viable classes, by 897 (2916-2019) for C(1) TR94-1 and by $742(1786-1044)$ for C(1)TR94-2.

Thus, as with single rings (Mongan 1933; Novitski 1951, 1955) and reversed compound rings (SANDLER 1957) in Drosophila, tandem rings produce progenies inconsistent with the assumption of sister-strand crossing over but consistent with those of the orthodox rules.

It has already been shown that the exceptional patroclinous male class, which results from the fertilization by XY-bearing sperm of presumptive X-bearing ova that did not receive an $\mathrm{X}$ chromosome, must come from products that would have been lethal had they received an $\mathrm{X}$ centromere. These products are the triplering and the three classes of double second anaphase bridges (see Table 2). However, since $c_{2}$ in these experiments was virtually unity, the probability that the presumptive egg nucleus will receive a triple ring, $1 / 4\left(1-c_{2}\right) E_{2}$, is close to zero, and the exceptional patroclinous males must therefore come largely from the second anaphase bridge classes. It is now of interest to inquire from what type or types of bridges, and with what frequencies, nullo-X eggs are produced. To gain insight into this question, it is desirable to examine the frequency of exceptional patroclinous males coming from tandem ring derivatives in which either the exchange distribution or the array of lethal products or both are altered. To this end, females carrying C(1)TR94-2 were irradiated with approximately $2000 \mathrm{r}$ of $\mathrm{X}$ rays and their daughters were testcrossed so that we could look for induced stabilizations of the compound (i.e., for compounds producing few or no single rings). Seven stable compounds were recovered, and they were analysed cytologically to ascertain the cause of the stability.

Five of the stable derivatives were identical, and each exhibited a small inversion-like loop extending from $1 \mathrm{~F}$ to $5 \mathrm{E}$. From the very low incidence of singlering generation and from the fact that the single rings formed always carried $\operatorname{In}(1) 1 F ; 5 E$, we can infer that the stabilizing event was an asymmetrical exchange between the $1 \mathrm{~F}$ region near the centromere and the $5 \mathrm{E}$ region near the interstitial heterochromatin. This exchange produced a ring of the salivary chromosome constitution

$$
|1 \mathrm{~A}--5 \mathrm{E}| 1 \mathrm{~F}-1 \mathrm{~A}|\cdot 20-5 \mathrm{E}| 1 \mathrm{~F}-20 \mid \text {. }
$$

Here the centerpoint designates the position of the centromere, and the vertical lines new associations. This configuration is convertible to a single ring by an exchange in region $1 \mathrm{~F}-5 \mathrm{E}$ and reversibly convertible to other double-ring con- 
figurations by other types of exchange (see Novitski and Braver 1954). Recovery of five identical stabilizations indicates a premeiotic origin, either spontaneous or induced. We designate this compound C(1)94-2A.

A sixth stable derivative, C(1)94-2E, carried a complicated duplication in region 10-11, which has so far proven refractory to salivary analysis.

The seventh stabilization is a reversed ring, C(1)RR94-2F, which apparently arose by asymmetric exchange between the interstitial heterochromatin and the region of the pericentric heterochromatin between $1 \mathrm{~A}$ and the centromere. Thus, the two X's are joined at their left ends by interstitial heterochromatin and at their right ends by the centromere.

Finally, an eighth spontaneous stabilization, C(1)A, was recovered by $\mathrm{H}$. Armentrout; it apparently arose through an asymmetric crossover between the component arms of $\mathrm{C}(1) \mathrm{TR} 94$ in region $6 \mathrm{~F} 2-7 \mathrm{~A} 1$, producing a ring of the salivary chromosome constitution

$$
|1 \mathrm{~A}-6 \mathrm{~F} 2| 6 \mathrm{~F} 2-1 \mathrm{~A}|\cdot 20-7 \mathrm{~A} 1| 7 \mathrm{~A} 1-20 \mid \text {. }
$$

In addition, mitotic chromosome analysis has shown that all stabilizations are still ring chromosomes.

The results from crosses of females carrying these stabilized compounds, both with and without $y^{+} \cdot Y^{\mathrm{L}}$, are compared in Table 10 with the data from C(1) TR94-2, the tandem ring from which the stabilizations were derived. The degree of stabilization is evident from the reduction in the size of single-ringbearing classes which is accompanied by increased recovery of double-ring-bearing females. The proportion of double rings recovered in every progeny from stabilized $\mathrm{C}(1) / \gamma^{+} \cdot \mathrm{Y}^{\mathrm{L}}$ females exceeds the $50 \%$ maximum that can be expected from the sister-strand exchange model which results when $E_{0}=1$ and one-half the double rings are lost by sister-strand exchange. A comparison of the results

\section{TABLE 10}

The results from crosses of females carrying the various stabilized double-ring derivatives of $C(1) T R 94-2$ with and without $\mathrm{y}^{+} . Y^{L}$ by $X Y, \mathrm{y}$ B/O males. For comparison, the data from C(1)TR94-2 (Tables 6 and 7) are also given

\begin{tabular}{|c|c|c|c|c|c|c|}
\hline \multirow[b]{2}{*}{$\begin{array}{l}\text { Constitution of } \\
\text { parental female }\end{array}$} & \multicolumn{6}{|c|}{ Progeny } \\
\hline & $\begin{array}{c}\text { Regular } \\
\text { patroclinous } \\
\text { males }\end{array}$ & $\begin{array}{l}\text { Exce } \\
\text { patroclin } \\
\text { No. }\end{array}$ & $\begin{array}{l}\text { tional } \\
\text { ous males } \\
\text { Percent }\end{array}$ & $\begin{array}{c}C(1) \\
\text { females }\end{array}$ & $\begin{array}{l}\mathrm{R}(1) \\
\text { males }\end{array}$ & $\begin{array}{l}R(1) /+ \\
\text { females }\end{array}$ \\
\hline $\mathrm{C}(1) \mathrm{TR} 94-2 / \gamma+\cdot \mathrm{YL}$ & 2830 & 393 & 14 & 558 & 1014 & 1238 \\
\hline $\mathrm{C}(1) \mathrm{TR} 94-2 \mathrm{~A} / y+\cdot \mathrm{Y}^{\mathrm{L}}$ & 19737 & 2025 & 10 & 12183 & 54 & 114 \\
\hline $\mathrm{C}(1) \mathrm{TR} 94-2 \mathrm{E} / y+\cdot \mathrm{Y}^{\mathrm{L}}$ & 3069 & 366 & 12 & 1753 & 23 & 247 \\
\hline $\mathrm{C}(1) \mathrm{RR} 94-2 \mathrm{~F} / y+\cdot \mathrm{Y}^{\mathrm{L}}$ & 5158 & 544 & 11 & 2701 & 0 & 0 \\
\hline C(1) TR94-2/0 & 8549 & ... & & 992 & 706 & 1305 \\
\hline C(1) TR94-2A/0 & 12117 & & & 7000 & 85 & 124 \\
\hline G(1)TR94-2E/0 & 1185 & $\cdots$ & . & 720 & 8 & 54 \\
\hline $\mathrm{C}(1) \mathrm{RR} 94-2 \mathrm{~F} / 0^{*}$ & 2112 & ... & & 923 & 0 & 0 \\
\hline $\mathrm{C}(1) \mathrm{A} / 0$ & 831 & $\ldots$ & & 416 & 0 & 0 \\
\hline
\end{tabular}

* Data from Sandier (1965). 
from the various lines reveals that in these chromosomes, which must have variable tetrad distributions as well as different arrays of bridge products, the incidence of exceptional patroclinous males is effectively constant, varying only from 11 to $14 \%$. This constancy provides further evidence that nullo-sex-chromosome ova do not arise regularly from any particular class or combination of classes of meiotic products that would otherwise be viable, and these ova must therefore come from the anaphase bridge classes.

Moreover, since the various ring types tested produce structurally different kinds of bridges (e.g., reversed rings produce only $2: 2$ bridges, whereas tandem rings produce $1: 1,2: 1$, and $3: 1$ bridges), the constant frequency of exceptional patroclinous males implies that no one type of bridge regularly gives rise to nullo-X ova, but rather that these ova come from a fraction of all (or most) bridge types. Since total bridges (see Table 2) are $1 / 2 E_{1}+3 / 8 E_{2}$ for tandem rings and $1 / 2 E_{1}+1 / 2 E_{2}$ for reversed rings (Novirski 1954), it is evident that this total will not vary greatly with exchange distribution (even though the classes will change) provided that $E_{0}$ is low. This relation explains the constancy of the exceptional patroclinous male class, even where the exchange distribution varies. Also, from the estimates of $E_{1}$ and $E_{2}$ and the observed number of exceptional patroclinous males, it follows that $38 \%$ of the bridges from C(1)TR94-1 and $44 \%$ of those from C(1)TR94-2 produce nullo-X eggs.

\section{Analysis of C(1)TR/0 Data}

In crosses of $\mathrm{C}(1) \mathrm{TR} / y^{+} \cdot \mathrm{Y}^{\mathrm{L}}$ females, the $y^{+} \cdot \mathrm{Y}^{\mathrm{L}}$-bearing eggs (which are recovered as regular patroclinous males) give a measure of the expected total of presumptive X-bearing ova; that is, they represent the class with which all other classes are compared. In C(1) TR/0 crosses, the patroclinous male class contains, in addition to the presumptive $\mathrm{Y}$-bearing ova (i.e., the presumptive non-X-bearing ova), presumptive $\mathrm{X}$-bearing ova from which the $\mathrm{X}$ has been lost, making a rigorous analysis impossible and others hazardous. While this difficulty is present in any cross involving compound X's, it is especially troublesome in the case of the tandem ring because (1) as has been shown in the preceding section, a substantial fraction of the second anaphase bridges gives rise to nullo-X eggs, and (2) the absence of $y^{+} \cdot Y^{\mathrm{L}}$ evidently has a drastic effect on the exchange distribution, making it impossible to utilize the estimates of $E_{i}$ from $\mathrm{C}(1) \mathrm{TR} / y^{+} \cdot \mathrm{Y}^{\mathrm{L}}$ crosses.

This latter point follows directly from the fact that the frequency of homozygosis is a direct measure of double exchange and is sharply reduced in the absence of the homolog (Table 11). That this is a real effect on exchange and not indicative of strand preference or chromatid interference is indicated by the same reduction seen in the frequency of transposition in the absence of $y^{+} \cdot \mathrm{Y}^{\mathrm{L}}$ (see measurements of recombination above). Although this effect is sufficient to indicate that the absence of a homolog in the TR-bearing female affects the exchange distribution by reducing $E_{2}$, it provides no information on the concomitant changes in $E_{0}$ and $E_{1}$. 
TABLE 11

The effect of the presence of $y^{+} \cdot Y^{L}$ in the compound-bearing female on the frequency of homozygosis in tandem compound ring $X$ chromosomes

\begin{tabular}{lccccc}
\hline \multirow{2}{*}{$\begin{array}{c}\text { Constitution of } \\
\text { parental female }\end{array}$} & $c v$ & $s n$ & $v$ & $g$ & $s d$ \\
\cline { 2 - 6 } & 0.8 & 0.7 & 2.2 & 1.2 & 1.1 \\
C(1) TR94-1/0 & 2.3 & 2.7 & 4.7 & 3.6 & 1.6 \\
C(1) TR94-1/y+.YL & 0.9 & 0.6 & 2.5 & 1.9 & 1.0 \\
C(1) TR94-2/0 & 2.2 & 4.0 & 5.3 & 4.2 & 2.7 \\
C(1) TR94-2/y+.YL & & & \\
\hline
\end{tabular}

- Homozygosis is computed here as the number of females homozygous for the marker divided by the total number of TR-bearing females.

It has been noted previously that reversed acrocentric compound $\mathrm{X}$ chromosomes (SANDLER 1954) and reversed compound ring X chromosomes (SANDLER 1957,1965 ) also show a markedly reduced frequency of double exchange tetrads in $\mathrm{C}(1) / 0$ as compared to $\mathrm{C}(1) / y^{+} \cdot \mathrm{Y}^{\mathrm{L}}$ females. In the case of reversed acrocentrics, this effect is seen in those compounds that also show an abnormal exchange distribution characterized by a deficiency of rank 1 tetrads. But when the long arm of the Y chromosome is appended as a second arm to the reversed acrocentric, both the abnormal exchange distribution and the effect of the homolog on exchange disappear; this suggests that the two effects are causally related (SANDLER 1958). However, both the tandem ring compounds analysed here and the derivative reversed ring, C(1) RR94-2F (SANDLER 1965), exhibit nearly orthodox tetrad distributions, although showing a marked effect of the homolog on exchange. Apparently, then, the two anomolous phenomena are causally distinct, and the $Y$ arm on the reversed acrocentric affects both of them.

Yet another complication exists in the analysis of results from $C(1) \mathrm{TR} / 0$ crosses. It has been shown by LindsLeY and SANDLER (1965) that single ring X chromosomes, newly generated by tandem metacentrics (including the tandem metacentric from which these TR's were produced), are lost with a variable frequency with the consequent production of nullo-X eggs. In the present analysis, this has the double consequence of adding yet another unknown component to the patroclinous male class; and at the same time, reducing the single ring class, rendering it unusable, in a simple way, for computing exchange values.

Finally, and for reasons completely unknown to us, C(1)TR94-1 and C(1) TR94-2, although behaving alike when tested with $y^{+} \cdot \mathrm{Y}^{\mathrm{L}}$, behave quite differently in the absence of a homolog. A part of this difference-specifically, the relative recovery of patroclinous males:compound-bearing females:single-ringbearing females - can be explained in terms of differing amounts of single ring loss; this will be shown below. However, we must also consider the very curious difference in the recovery of single rings in females as compared to male in C (1) TR94-2. This difference is seen both in the extensive data given in Table 8 and in the initial female (94-2) whose progeny are recorded in Table 5. This effect is especially peculiar because the ratio of single rings recovered in females 
as compared to males represents the viability of the rings in the two sexes and/or the ratio of $\mathrm{XY}$-bearing to nullo-XY sperm from the male. Because the latter is almost certainly approximately $1: 1$, it appears that a large proportion of the generated single rings are not recoverable as sons from C(1)TR94-2/0 females. The reduced recovery of single-ring-bearing sons cannot, however, be explained by the presence of a lethal that has appeared in the C(1)TR94-2 stock, because (1) the markers from the TR appear in single-ring-bearing males with the expected frequencies relative to one another and (2) the deficiency of ring-bearing males seen in the progeny of the original C(1)TR94-2/0 females (Table 5) disappears when $y^{+} \cdot Y^{L}$ is introduced into the female (Table 7 ).

If this last effect is ignored (i.e., if the single-ring-bearing females are used as a measure of the recovery of single rings), then it is possible to interpret the $\mathrm{C}$ (1) TR/0 data by assuming that (1) there is a probability of single ring loss leading to nullo-X eggs that is peculiar to each line and occurs only in the absence of a homolog, (2) $c_{1}=c_{2}=1$, as was the case when $y^{+} \cdot \mathrm{Y}^{\mathrm{L}}$ was present, and (3) the probability that a second anaphase bridge will give rise to a nullo- $\mathrm{X}$ egg is the same as when $y^{+\cdot Y^{L}}$ was present $(38 \%$ for C(1)TR94-1 and $44 \%$ for C(1) TR94-2; see above).

From the equations given in Table 2 , if we allow $c_{1}=c_{2}=1, r$ to be the fraction of second anaphase bridges that give rise to nullo-X eggs and $s$ to be the fraction of loss of newly generated single rings (also leading to nullo- $\mathrm{X}$ eggs), then

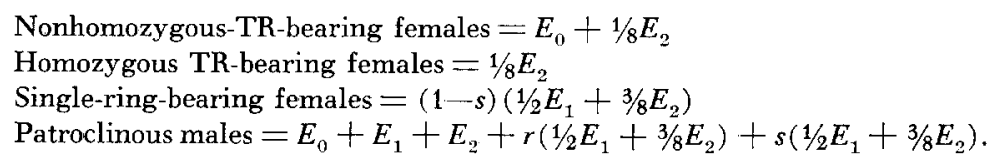

Solving, we find for the case of C(1) 94-1, where $r=0.38: E_{0}=0.24, E_{1}=0.68$, $E_{2}=0.08$, and $s=0.09$, and for the case of C(1) TR94-2, where $r=0.44: E_{0}=$ $0.14, E_{1}=0.79, E_{2}=0.06$, and $s=0.50$.

Thus, it can be seen that the $\mathrm{C}(1) \mathrm{TR} / 0$ data are interpretable in terms of single ring loss. However, it is again evident that in the absence of a homolog, C(1) TR94-1 and C(1)TR94-2 differ markedly; here the difference lies in the amount of ring loss that one must assume (it is nevertheless interesting that the two tetrad distributions remain similar, as was the case when $y^{+\cdot} \mathrm{Y}^{\mathrm{L}}$ was present). Since both lines arose from the same tandem metacentric compound $\mathrm{X}$ chromosome by an exchange between the tips of the elements (see Figure 2), we can conclude that the difference between them must reside in the interstitial heterochromatin and, further, that one or both of the TR's arose by a heterochromatic exchange.

In previous investigations of the fate of second anaphase bridges from tandem metacentric compound X chromosomes, it was concluded that they are always, or almost always, lethal. Bridges from tandem metacentrics are either two centromeres connected by one chromatid strand or a 1:1 double bridge of the same constitution as the $1: 1$ bridge produced by tandem rings. In the case of tandem rings, it is clear that some $40 \%$ of the bridges in general are not lethal but instead give 
rise to nullo-X eggs. To reconcile these two observations it is necessary to suppose that either the nonlethal double bridges in the tandem ring are a fraction of only the 2:1 and 3:1 types or that a fraction of the 1:1 double bridges in tandem metacentrics behaves as Novitski (1955) postulated (i.e., give rise to nullo-X eggs). The inclusion or exclusion of a fraction of the 1:1 bridge class as nullo-X eggs would not materially affect the calculations presented in the case of either tandem metacentrics or tandem rings.

Finally, it should be noted that tandem rings, in common with single and reversed rings, are recovered with a much reduced frequency in females homozygous for $c 3 G$, an autosomal recessive that eliminates meiotic exchange (SANDLER 1965). It seems, in fact, that in a variety of circumstances (e.g., with $c 3 G$, in the absence of a homolog, and from particular constructions) tandem compound ring $\mathrm{X}$ chromosomes are transmitted with a reduced frequency. What, if anything, is common to these circumstances is completely unknown.

We are most grateful to Mrs. Averil Rosenfeld and to Mr. Joseph Orem for all the hours they spent helping to collect the data presented here.

\section{SUMIMARY}

Well-marked tandem compound ring $\mathrm{X}$ chromosomes were synthesized and their behavior studied. The results lead to the following conclusions: (1) Tandem rings of different origin have different probabilities of transmission; rings with a common origin have the same transmission probability. (2) The data are consistent with the conventional rules of crossing over and inconsistent with the LiNDEgren-Schwartz model of sister-strand crossing over. (3) Tandem rings exhibit an exchange distribution similar to those of free X's, attached X's, and tandem acrocentric and tandem metacentric compound $X$ chromosomes. (4) As with other tandem compounds, when a single $\mathrm{X}$ separates from a compound double or triple $\mathrm{X}$ chromosome at second anaphase, it is included in the functional egg nucleus with a probability close to or equal to one. (5) Approximately $40 \%$ of the double second-anaphase bridges are excluded from the functional egg nucleus, producing nullo-X eggs. (6) The data are such as to exclude, at least when the compound-bearing females carry a $\mathrm{Y}$ chromosome, any significant loss of single or double rings due to the formation of interlocked complexes. (7) The presence of a $\mathrm{Y}$ chromosome in the compound-bearing female results in a doubling of the frequency of two-exchange tetrads as measured by homozygosis. (8) In the absence of a $\mathrm{Y}$ chromosome, the fraction of recovered tandem rings and derivative single rings changes; a model based on the loss of newly generated single rings is consistent with the data.

\section{LITERATURE CITED}

Beadle, G. W., and S. Emerson, 1935 Further studies of crossing over in attached X chromosomes of Drosophila melanogaster. Genetics 20 : 192-206.

LINDEGREN, C. C., and G. LINDEGREN, 1937 Non-random crossing over in Neurospora. J. Heredity 28: 105-113. 
LindsLey, D. L., and L. SANDLER, 1963 The construction of the compound X chromosomes in Drosophila melanogaster by means of the Bar Stone duplication. pp. 390-403. Methodology in Basic Genetics. Edited by W. J. Bundetre. Holden-Day, San Francisco.

Lindsley, D. L. and L. SANDLER, 1965 Meiotic behavior of tandem metacentric compound $\mathrm{X}$ chromosomes in Drosophila melanogaster. Genetics 51 : 223-245.

Morgan, L. V., 1933 A closed X chromosome in Drosophila melanogaster. Genetics 18: 250-283.

Novitski, E., 1951 Non-random disjunction in Drosophila. Genetics 36: 267-280. - 1954 The compound X chromosomes in Drosophila. Genetics 39:127-140. — 1955 Genetic measures of centromere activity in Drosophila melanogaster. J. Cellular Comp. Physiol. 45, Suppl. 2: 151-169.

Novitski, E., and G. BrAver, 1954 An analysis of crossing over within a heterozygous inversion in Drosophila melanogaster. Genetics 39: 197-209.

NovitSKi, E., and L. SANDLER, 1956 Further notes on the nature of non-random disjunction in Drosophila melanogaster. Genetics 41: 194-206.

SANDLER, L., 1954 A genetic analysis of reversed acrocentric compound $\mathrm{X}$ chromosomes in Drosophila melanogaster. Genetics 39: 923-942. __ 1957 The meiotic behavior of reversed compound ring $\mathrm{X}$ chromosomes in Drosophila melanogaster. Genetics 42: 764 782. - 1958 Genetic studies on exchange in the compound X chromosomes of Drosophila melanogaster. Cold Spring Harbor Symp. Quant. Biol. 23: 211-223. — 1965 The meiotic mechanics of ring chromosomes in female Drosophila melanogaster. Natl. Cancer Inst. Monograph 18: 243-272.

SANDleR, L., and G. Braver, 1954 The meiotic loss of unpaired chromosomes in Drosophila melanogaster. Genetics 39: 365-377.

SANDLER, L., and D. L. Lindsley, 1963 The meiotic behavior of tandem acrocentric compound X chromosomes in Drosophila melanogaster. Genetics 48: 1533-1543.

Schwartz, D., 1953 Evidence for sister-strand crossing over in maize. Genetics 38: 251-260.

Sturtevant, A. H., and G. W. Beadle, 1936 The relations of inversions in the $\mathrm{X}$ chromosome of Drosophila melanogaster to crossing over and disjunction. Genetics 21 : 554-604.

Weinstein, A., 1936 The theory of multiple-strand crossing over. Genetics 21 : 155-199.

Wershons, W. J., 1955 A comparative study of crossing over in attached $\mathrm{X}$ chromosomes in Drosophila melanogaster. Genetics 40: 918-936. 